\title{
The effect of Saqez (Pistacia atlantica) ointment on the treatment of nipple fissure and nipple pain in breastfeeding women
}

\author{
Nayereh Asadi ${ }^{1}$, Nourossadat Kariman ${ }^{2}$, Faraz Mojab ${ }^{3}$, Mohammad Amin Pourhoseingholi ${ }^{4}$
}

${ }^{1}$ M.Sc. of Midwifery, Student Research Committee, School of Nursing and Midwifery, Shahid Beheshti University of Medical Sciences, Tehran, Iran

${ }^{2}$ Ph.D. of Reproductive Health, Assistant Professor, Department of Midwifery and Reproductive Health, School of Nursing and Midwifery, Shahid Beheshti University of Medical Sciences, Tehran, Iran

${ }^{3}$ Ph.D. of Pharmacognosy, Professor, Department of Pharmacognosy, School of Pharmacy, Shahid Beheshti University of Medical Sciences, Tehran, Iran

${ }^{4}$ Ph.D., Gastroenterology and Liver Diseases Research Center, Research Institute for Gastroenterology and Liver Diseases, Shahid Beheshti University of Medical Sciences, Tehran, Iran

\section{Type of article: Original}

\begin{abstract}
Background: Nipple fissure is a common problem in breastfeeding women, and the main reason for the early discontinuation of breastfeeding.

Objective: To determine the effect of Saqez (Pistacia atlantica) ointment on the treatment of nipple fissure and nipple pain in breastfeeding women.

Methods: This randomized clinical trial was conducted on 100 subjects admitted to the health centers in Tehran, Iran from mid-July to mid-November 2015. The subjects were randomly divided into two equal groups of 50 for the Saqez ointment group and the control group. The subjects were divided into the two groups through random allocation in Excel. The subjects were monitored on day 1, 3 and 7. Data were analyzed in SAS using the Cumulative Logit model and in SPSS-21 using Mann-Whitney, independent-samples t-test, the Chi square and Fisher's exact test.

Results: No significant differences were observed between the two groups in terms of their demographic and fertility characteristics. The Cumulative Logit model showed that high levels of nipple fissure and pain were significantly less frequent in the Saqez group compared to the control group $(\mathrm{p}<0.001)$. There was about $83 \%$ reduction in the severity of fissure and $85 \%$ in the severity of pain in the Saqez group compared to the control group $(\mathrm{p}<0.001)$.

Conclusion: Saqez ointment is more effective in the treatment of nipple fissures and pain than breast milk. As this study was done for the first time, judgment about the conclusive efficacy of Saqez ointment on the nipple fissure, needs further similar studies.

Trial registration: The trial was registered at the Iranian Registry of Clinical Trials (http://www.irct.ir) with the Irct ID: IRCT2015080723535N1.

Funding: The authors received no financial support for the research, authorship, and/or publication of this article. Keywords: Nipple injuries, Pain, Ointments, Pistacia, Breast feeding
\end{abstract}

\section{Introduction}

The mother's breast milk is the ideal nutrition for the growth and development of newborns, and has an unrivalled biological and emotional effect on the health of the mother and the newborn. Compared to powdered milk, breast

\section{Corresponding author:}

Assistant Professor Dr. Nourossadat Kariman, Department of Midwifery and Reproductive Health, School of Nursing and Midwifery, Shahid Beheshti University of Medical Sciences, Tehran, Iran.

Tel:+98.2188202512, Fax: +98. 2188202516, Email: n_kariman@sbmu.ac.ir, n_kariman@yahoo.com

Received: April 16, 2017, Accepted: June 16, 2017, Published: August 2017

iThenticate screening: June 06, 2017, English editing: July 02, 2017, Quality control: July 12, 2017

This article has been reviewed / commented by four experts

(C) 2017 The Authors. This is an open access article under the terms of the Creative Commons Attribution-NonCommercialNoDerivs License, which permits use and distribution in any medium, provided the original work is properly cited, the use is non-commercial and no modifications or adaptations are made. 
milk has countless proven developmental, social, economic and health benefits (1). Exclusive breastfeeding is one of the key factors for reducing neonatal mortality and morbidity (2) that has enumerable benefits for the mother as well, including reduced postpartum hemorrhage and reduced risk of breast and ovarian cancer and osteoporosis (3). Breast conditions and problems are among the most important problems that can occur during lactation, especially in the first few days of breastfeeding (4). Nipple fissure and sore nipples are common complaints among lactating women, and are the second leading cause of the early discontinuation of breastfeeding after insufficient milk supply and construe the main reason for mothers' tendency to use artificial feeding. Nipple soreness occurs mostly between days three and seven after childbirth and may persist for as long as six weeks postpartum in some women (5). Around $80 \%$ to $90 \%$ of lactating women experience different types of nipple soreness and $26 \%$ suffer from highly painful nipple fissures (6). Untreated fissures may lead to complications such as severe pain, bleeding and inadequate milk removal, mastitis and breast abscess (7). The possible causes of breast fissure and pain include anatomical causes such as poor breastfeeding latch and incorrect breastfeeding position (6), short frenulum, very small tongue, the use of a breast pump (7), Candida albicans infection (8), the use of a pacifier and powdered milk (9) and pulling out the breast before the baby has finished suckling (10). There are various herbal, medicinal and non-medicinal remedies for the treatment of breast fissure and pain, including warm water compress and tea bags $(11,12)$, Curcumin (13), Lanolin and breast milk $(14,15)$, lanolin and breast shell $(15,16)$, topical antibiotic ointments (17), breast shell (18, 19), D \& E ointment (20), Apicar ointment (21), phototherapy (22), silver cap (23), Collagenase (24), Dexpanthenol (4, 24), menthol essence (5), Aloe Vera gel (2) and breast milk $(6,25)$. None of the previous studies have proposed a completely effective cure for nipple soreness, and nipple fissure continues to be a serious clinical problem. Definitive judgment about the effectiveness of these interventions requires further and more accurate studies with sufficient sample sizes $(26,27)$. Moist wound healing is currently a recommended method that increases the skin's moisture levels and accelerates healing without causing scabs and dry skin (21). Plant extracts form the basis of topical wound care due to their flavonoid and phenolic content (28). Saqez ( Pistacia atlantica), from the Anacardiaceae family, is a plant indigenous to a number of countries such as Iran, Iraq and Turkey. Saqez is an oleoresin that comes in hard white sheets or as a yellow liquid. It is made from scratching the trunks of Baneh trees. Saqez contains alpha-Pinene and triterpenoid compounds with strong antimicrobial and antioxidant properties and thus cures wounds. The ointment of Saqez, melted with tallow, is effective in the treatment of bursting nails and chronic anal fissure (29-31). Given the importance of breastfeeding and the high prevalence of breast fissure in lactating women, and since no cures without side-effects have yet been proposed to heal breast fissure in the shortest possible time, and considering that Saqez is a traditional wound-healing substance whose ointment (consisting of Saqez, beeswax and ghee) has long been used in West Azerbaijan Province of Iran for the successful treatment of fissures, and given the lack of studies on the effect of Saqez ointment on breast fissures, the present study was conducted to determine the effect of Saqez (Pistacia atlantica) ointment on the treatment of nipple fissure and nipple pain in breastfeeding women (30).

\section{Material and Methods}

\subsection{Trial design and participants}

This study was a randomized clinical trial that was conducted from mid-July to mid-November 2015. This clinical trial was conducted in health centers affiliated to Shahid Beheshti University of Medical Sciences in Tehran (Nader and Samarghandi centers). The research population was comprised of eligible breastfeeding women presenting to the select health centers on their postpartum day three, for a hypothyroidism screening test for their newborns (a routine neonatal screening test in Iran) and were assessed for their inclusion and exclusion criteria. The eligible women who were willing to participate and submitted their written consent were enrolled in the study. The women's level of nipple pain during breastfeeding was measured on the pain scale and their fissure was measured on the Storr scale.

\subsection{Selection criteria}

The study inclusion criteria in this study were: 1) being a lactating mother aged over eighteen years old, 2) with nipple fissure and pain and a minimum score of three on the Storr scale for assessing fissure, 3) being of Iranian nationality, 4) being literate, 5) having had a singleton pregnancy, 6) having given birth to a healthy term infant, 7) exclusive breastfeeding, 8) having a birth weight more than $2500 \mathrm{~g}$ but lower than $4000 \mathrm{~g}, 9$ ) no oral, palate or maxillofacial abnormalities in the newborn, 10) no nipple abnormalities in the mother and, 11) no history of allergy to Saqez ointment. The last criterion was determined by asking the participants if they had a history of allergy to ointments containing Saqez. In addition, for the detection of allergy to Saqez ointment, the participants were asked to apply about 0.5 centimeters of Saqez ointment on the skin of the forearm and if there were no allergy reactions within 6 hours after applying the ointment, they could use the ointment on the nipple fissure. The study exclusion 
criteria consisted of the newborn's use of a pacifier or milk bottle during the study, the newborn's illness during the study, showing allergic reactions to Saqez ointment, the mother's use of a breast pump or plastic nipple, the mother's infection with mastitis, abscess or fungal infection in the breast, the use of the recommended treatment less than three times per day and the mother's use of other cures.

\subsection{Interventions}

In this clinical trial, 168 breastfeeding mothers were visited at the health centers in 2015, and 68 women were excluded because they declined to participate or they met one or more of the exclusion criteria. In stage one (on the day of admission), the researcher examined the newborns for oral thrush and potential oral and maxillofacial abnormalities and examined the mothers' two nipples and assessed and recorded the severity of their nipple fissure according to the Storr scale. Both groups then received face-to-face instructions on breastfeeding techniques and hygiene with a free educational pamphlet. The researcher then asked each mother to breastfeed her newborn, and assessed her breastfeeding technique and asked her to judge her level of pain on the pain scale. The control group was advised to draw two to three drops of their breast milk with clean hands and to apply it on their nipple fissure and areola and to let it air-dry immediately after each breastfeeding. Saqez ointment was distributed to the intervention group free of charge at the beginning of the experiment and the mothers in this group were instructed on how to detect allergic reactions and begin the treatment if not witnessing any such reactions. They were also advised to wash their hands immediately after each breastfeeding and to apply a fingertip of Saqez ointment on their nipple fissure and areola three times per day. The Saqez ointment used in this study was made by combining $7 \mathrm{~g}$ of Saqez, $7 \mathrm{~g}$ of beeswax and $10 \mathrm{~g}$ of ghee. These substances were procured from Urmia pharmaceutical market and their ointment was prepared in 24-gram tins at the Pharmacognosy Department of Shahid Beheshti School of Pharmacy. The active compound of Saqez was $25 \mathrm{mg}$ of alpha-Pinene in $100 \mathrm{~g}$, which was analyzed in this study. The mothers were advised by the researcher to shower with warm water every day and keep their nipples dry and to refrain from the use of soap or other materials that could cause the dryness of the nipple skin. The mothers were asked to visit again on the third and seventh days of the intervention in order to have their first and second follow-ups. In these follow-ups, the mothers' breastfeeding technique, their level of nipple pain during breastfeeding and their nipple fissure were assessed and recorded again with the help of a research collaborator who was blinded to the groupings. The demographic and obstetric questionnaire was completed for the mothers and a checklist of side-effects and satisfaction with the treatment (whether or not she experienced any allergies, infections, itching, stinging, burning, dryness and other side-effects at the site of the fissure, and whether or not she was happy with the treatments) was then given to the mothers to complete and return to the researcher by the end of the study (on day seven). The validity of the questionnaires was qualitatively assessed using the content validity method. The severity of nipple fissure was assessed according to the Storr scale. The Storr scale has five degrees, from zero to four. A painless nipple with normal color is given a score of zero, a slightly reddened nipple and pain at the beginning of breastfeeding (the first five to ten seconds) is given a score of one, a reddened nipple with pain at the beginning of and in the intervals between breastfeeding is given a score of two, a nipple beginning to fissure with pain at the beginning of and in the intervals between breastfeeding is given a score of three and a nipple fissure and nipple soreness with pain at the beginning of and in the intervals between breastfeeding is given a score of four. The Storr scale was validated in 1988 by Storr using the content validity method and by measuring its Cronbach's alpha coefficient (32); the scale has also been confirmed for use in Iran in many studies by measuring its content validity (7). The participants were asked to judge their level of pain on the pain scale. It has ten points; zero point is given for 'no pain', one, two and three points are given for 'almost bearable mild pain of varying degrees', four, five and six points for 'relatively bearable moderate pain of varying degrees' and seven, eight, nine and ten points for 'usually intolerably severe pain of varying degrees', where the score of ten indicates extremely severe and intolerable pain. Previous studies have shown that the pain scale has an adequate validity too (33) and has been used in several studies for the assessment of the severity of breast pain (34). Farar et al. used the test-retest method to confirm the reliability of the pain scale and calculated its correlation coefficient as 0.83 (35). In one study, Tafazoli et al. examined the parallel-forms reliability of the scale (7). In the present study, inter-rater consistency was used to confirm the reliability of the pain scale and Storr scale. Their correlation coefficient were calculated as 0.86 and 0.79 , respectively.

\subsection{Outcomes}

The primary outcomes of our analyses were treating nipple fissure and reducing nipple pain. Also, the secondary outcomes from the analyses were the adverse effects of the interventions during the course of treatment (whether or not they experienced any allergies, infections, itching, stinging, burning, dryness and other side-effects at the site of the fissure) and patients' satisfaction with the treatment in terms of convenience of use. 


\subsection{Sample size}

The sample size of this study was estimated to be 100 with a potential sample loss of $10-15 \%$ in the follow-up stages. We had two groups of 50. This sample size was calculated according to the results of previous studies (36, 37 ) with a confidence interval of $95 \%$, the test power of $80 \%, \alpha=0.05$ (38).

\subsection{Randomization and blinding}

In this clinical trial, eligible women were selected through purposive sampling with the baseline minimum score of three on the Storr scale for assessing nipple fissure. For this, the participants were allocated randomly to receive either Saqez ointment or the breast milk. The allocation of the participants into two groups was done using Excel software. Thus, in Excel program, in the first column titled cases, 100 cases were identified from 1 to 100. In the second column titled codes, code 1 was considered for the first 50 cases, and code 2 , for the second 50 cases, then in the third column, codes 1 and 2 were randomly allocated to 100 cases using random function. According to the prepared random list, participants were put in either the Saqez or the breast milk group in order of inclusion. In the first and second follow-ups breastfeeding technique, level of nipple fissure and pain were assessed and recorded with the help of a research collaborator who was blinded to the groupings.

\subsection{Statistical methods}

The data collected were analyzed in SPSS-21. The descriptive assessment of the data and the demographic findings were conducted using the mean and standard deviation, frequency tables and statistical charts. The comparison of the groups and inferential assessments were performed in SAS using the Cumulative Logit model and in SPSS-21 using Mann-Whitney, independent-samples t-test, the Chi square and Fisher's Exact test. The level of statistical significance was set at $P<0.05$. Cumulative Logit model was used in this study to compare the two groups in terms of nipple fissure and nipple pain. This model is used to measure the effect of different methods of treatment through repeated measurements over time (39 and 40). In this model, we used exponential function changed into odds ratio. Also, before performing the statistical analysis, the normality of the quantitative variables' distribution was examined using the K-S test.

\subsection{Research ethics}

This trial was approved by the ethical committee of Shahid Beheshti School of Nursing and Midwifery (code: SBMU2.REC.1394.10) and registered at the Iranian Registry of Clinical Trials (IRCT2015080723535N1). Participants enrolling in this study were asked about adverse reactions of the intervention in each visit. In the case of severe pain over the course of the study, the subjects were allowed to use analgesics, but had to record the type and number of analgesics taken, and measure their severity of pain immediately before and half an hour after their use on the pain scale according to the instructions given. The mothers who failed to achieve full recovery from nipple fissure and pain by the seventh day were referred to a specialist.

\section{Results}

In this clinical trial, 168 breast feeding women were visited, 68 of whom were excluded. The remaining 100 women were enrolled and allocated randomly into two groups of fifty. Eight samples in the Saqez group and two samples in the control group were lost to the first follow-up. So, 42 participants in the Saqez group and 48 in the control group were analyzed. Figure 1 shows the CONSORT flow diagram of the trial. Table 1 presents the demographic characteristics of the participants. As specified in Table 1, the two groups (the Saqez ointment and the control group) showed no significant difference in demographic variables. Table 2 shows a lower frequency of severe and very severe pain in the ointment group compared to the control group; moreover, there was $85 \%$ reduction in the severity of pain in the Saqez group compared to the control group $(\mathrm{p}<0.001),[\mathrm{OR}(95 \% \mathrm{CI})=0.151(0.08-0.78)]$ and the value less than one shows a reduced severity of pain in the Saqez group. Figure 2 shows a reduced mean severity of pain over time in both groups, but a greater reduction has been achieved in the Saqez group. Table 2 shows a lower frequency of severe fissure in the Saqez group compared to the control group; moreover, there was $83 \%$ reduction in the severity of fissure in the Saqez group compared to the control group $(\mathrm{p}<0.001)$, [OR $(95 \% \mathrm{CI})=$ $0.174(0.08-0.35)]$, and the value less than one shows a reduced severity of fissure in the Saqez group. The OR indicated that the chance of pain severity and fissure severity were decreasing through time in the Saqez group, compared to the control group. According to Figure 3, the mean severity of fissure reduced over time in both the Saqez and control groups, but the highest reduction was achieved in the Saqez group. In the follow-up on the third day, full recovery from fissure was observed in $61.9 \%$ of the cases in the Saqez group and in $27.1 \%$ of the controls, 
which suggests the faster onset of the healing properties of Saqez and the shorter time it takes to effectively heal fissures.

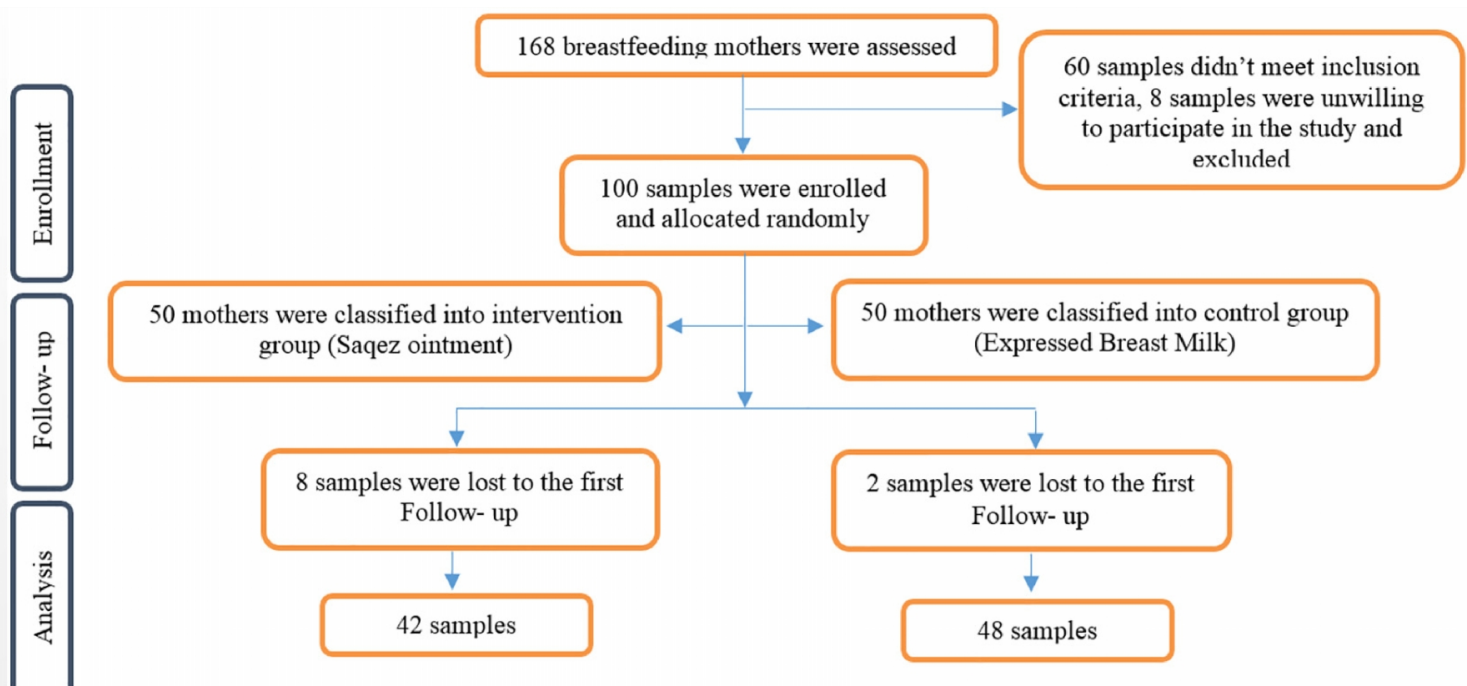

Figure 1. CONSORT flow diagram of the trial

Table 1. Demographic characteristics of the participants

\begin{tabular}{|c|c|c|c|c|}
\hline \multicolumn{2}{|l|}{ Variable } & $\begin{array}{l}\text { Saqez ointment group } \\
(\mathrm{n}=42)\end{array}$ & $\begin{array}{l}\text { Control group } \\
(\mathrm{n}=48)\end{array}$ & $\begin{array}{l}\mathrm{p}- \\
\text { value }\end{array}$ \\
\hline \multicolumn{2}{|l|}{ Age (years) } & $30.02 \pm 3.91$ & $28.65 \pm 4.64$ & 0.13 \\
\hline \multicolumn{2}{|l|}{ Body Mass Index } & $29.29 \pm 3.79$ & $28.13 \pm 4.31$ & 0.18 \\
\hline \multirow[t]{2}{*}{ Maternal Education Level } & Diploma or below & $22(52.4 \%)$ & $20(41.7 \%)$ & \multirow[t]{2}{*}{0.31} \\
\hline & University Degree & $20(47.6)$ & $28(58.3 \%)$ & \\
\hline \multirow[t]{2}{*}{ Mother's Occupation, n (\%) } & Housewife & $33(78.6 \%)$ & $40(83.3 \%)$ & \multirow[t]{2}{*}{0.56} \\
\hline & Employee & $9(21.4 \%)$ & $8(16.7 \%)$ & \\
\hline \multirow[t]{2}{*}{ Mother's Economic Status, n (\%) } & Low to Middle & $34(82.9 \%)$ & $36(75 \%)$ & \multirow[t]{2}{*}{0.36} \\
\hline & High Level & $7(17.1 \%)$ & $12(25 \%)$ & \\
\hline \multirow{2}{*}{$\begin{array}{l}\text { Number of previous pregnancies, } n \\
(\%)\end{array}$} & 1,2 & $36(85.7 \%)$ & $43(89.6 \%)$ & \multirow[t]{2}{*}{0.57} \\
\hline & 3,4 & $6(14.3 \%)$ & $5(10.4 \%)$ & \\
\hline \multirow[t]{2}{*}{ Type of delivery, n (\%) } & Vaginal & $6(14.3 \%)$ & $11(22.9 \%)$ & \multirow[t]{2}{*}{0.41} \\
\hline & C- Section & $36(85.7 \%)$ & $37(77.1 \%)$ & \\
\hline \multirow[t]{2}{*}{ History of abortions, $\mathrm{n}(\%)$} & Yes & $9(21.4 \%)$ & $8(16.7 \%)$ & \multirow[t]{2}{*}{0.59} \\
\hline & No & $33(78.6 \%)$ & $40(83.3 \%)$ & \\
\hline \multicolumn{2}{|l|}{ Age of the newborns (days) } & $5.38 \pm 3.80$ & $6.10 \pm 9.65$ & 0.65 \\
\hline \multicolumn{2}{|l|}{ Weight of the newborns (grams) } & $3240.24 \pm 335.22$ & $3137.29 \pm 423.87$ & 0.20 \\
\hline
\end{tabular}

Table 2. A comparison of the severity of nipple pain and fissure between the Saqez and control groups

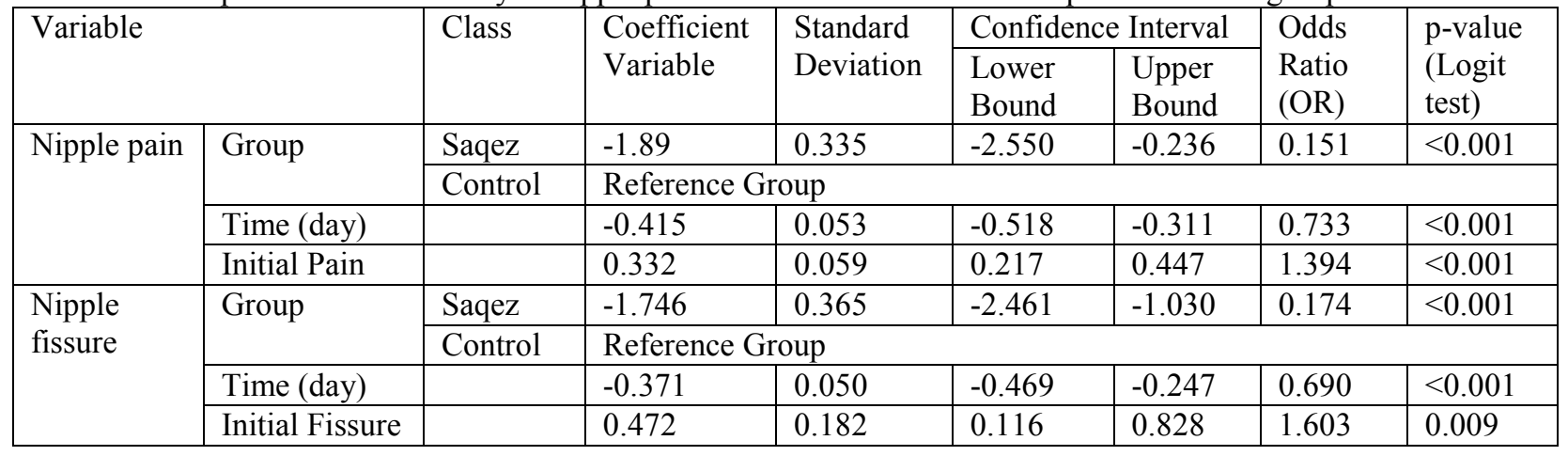


On the seventh day, an average of $52.4 \%$ of the cases in the Saqez group and an average of $17.75 \%$ of the controls experienced full recovery from pain, which indicates the higher rate of full recovery from pain on the seventh day in the Saqez group compared to the control group. No side-effects or allergies were observed in the Saqez group, while in the control group, stinging was reported in $10.4 \%(=0.05)$ and dryness in $8.3 \%(\mathrm{p}=0.12)$ of the cases, but the difference is not statistically significant. The Saqez group reported a greater satisfaction with their treatment than the control group ( $95.3 \%$ vs. $56.3 \%)$, suggesting a significant intergroup difference $(\mathrm{p}<0.001)$. A significant difference was also observed between the Saqez (95.2\%) and control (56.2\%) groups in terms of recommending their treatment $(p<0.001)$. The Saqez group used fewer analgesics than the control group $(57.1 \%$ vs. $66.7 \%)$, but this difference was not statistically significant $(\mathrm{p}=0.35)$.

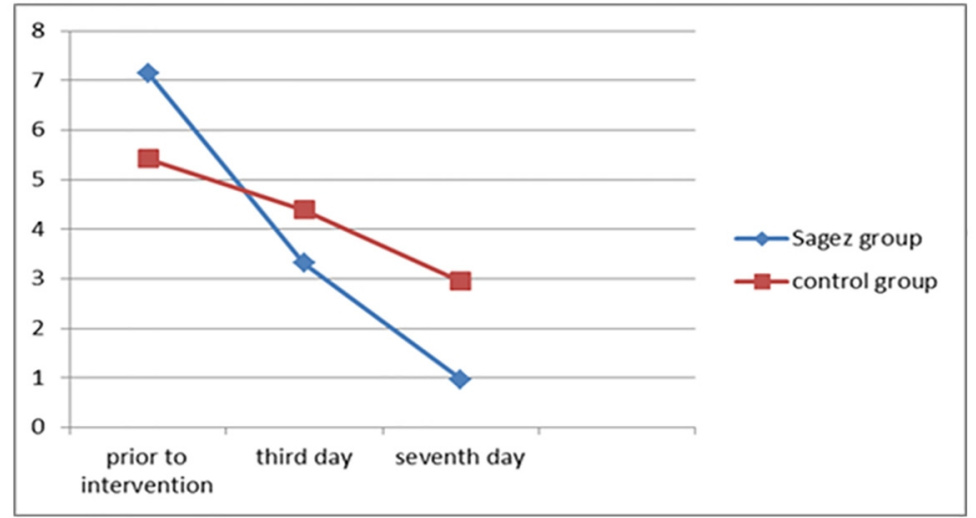

Figure 2. The trend of changes in the mean severity of pain score before the intervention and on post-intervention days three and seven in the Saqez and control groups

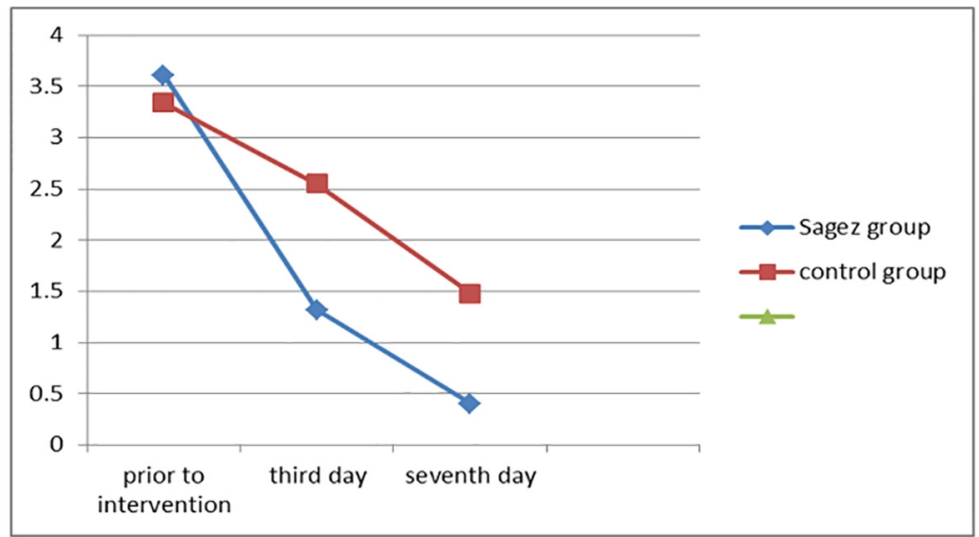

Figure 3. The trend of changes in the mean severity of fissure score before the intervention and on post-intervention days three and seven in the Saqez and control groups

\section{Discussion}

The present study showed that Saqez ointment is more effective than breast milk in reducing the severity of nipple pain and fissure. Before the present research, no studies had examined the effect of Saqez ointment on the severity of nipple pain and fissure. In 2013, Haghdoost et al. conducted a controlled study of the healing properties of Saqez and examined its dose-dependent effect in angiogenesis and healing skin burn wounds in rats and found that Saqez leads to an improved healing of burns. Their results showed that the healing effect of Saqez on burn wounds may be due to the better fibroblast and platelet-derived growth factors and the increased angiogenesis (31). In their review study, Bahmani et al. confirmed the anti-inflammatory, antimicrobial, antiviral, anti-fungal, antioxidant and anticancer properties of Saqez and its uses in both traditional and modern medicine in the treatment of skin wounds and fissures (30), which is consistent with the present findings. In a controlled, prospective, clinical trial, Abou-Dakn et al. concluded that lanolin is more effective than breast milk in reducing nipple pain and causing fast recovery from nipple fissures. In the lanolin group, recovery from pain was $65 \%(n=43)$ on the third day and $87 \%(n=66)$ on the 
seventh day (the second visit). In the same group (the lanolin group), the number of cases recovered from nipple fissure was 28 on the third day (the first visit) and 52 on the seventh day (41). In the present study, the number of cases recovered from nipple fissure was 52 on the third day and 72 on the seventh day in Saqez group. A comparison of the results of these two studies reveals the faster onset of the healing properties of Saqez compared to lanolin and the shorter time it takes to effectively heal fissures. The active compound in lanolin is ester, which is similar to the active compounds of Saqez, beeswax and ghee. Esters have wound healing properties in humid environments as well as anti-inflammatory and antimicrobial properties; moreover, they protect the skin and act as a barrier to restore it (9). As discussed earlier, in this study, Saqez ointment was prepared from a combination of Saqez, beeswax and ghee. Saqez contains alpha-Pinene, monoterpenoids and triterpenoids, which are responsible for its anti-inflammatory properties. The antimicrobial activity of Saqez, especially against gram positive and negative bacteria and helicobacter pylori, and its antiviral and anti-fungal properties are mostly due to the active compound of alpha-Pinene (29-31). Saqez has angiogenetic and wound healing properties and has traditionally been used to dress wounds (31). Beeswax contains monoesters, hydrocarbons, free fatty acids, di-esters and free fatty alcohols. Today, beeswax has many important applications as emulsifier, thickener and softener in pharmaceutical and cosmetic products (42) and is also used in the preparation of yellow ointments (43). With its saturated and unsaturated fatty acid content and vitamins A, D and E, ghee is known as a bio-stimulator for healing wounds (44). The present study used standard tools for measuring recovery and non-recovery from nipple fissure and pain. The follow-up durations and intervals were determined through the study of credible scientific sources. Fissure and pain levels were determined by the same researcher in all the follow-up stages and in all the samples. The study limitation included the uncontrollable and widely different reactions of individuals to pain (45). As this study was done for the first time, judgment about the conclusive efficacy of Saqez ointment on the nipple fissure, needs further similar studies.

\section{Conclusions}

With a maximum control of the confounding factors, the present findings showed that Saqez ointment obviates the severity of pain and heals nipple fissure in lactating women without imposing any side-effects on the mother or the newborn. Many studies have shown that each of the three constituent parts of Saqez ointment contains separate active ingredients for healing wounds and reducing the severity of pain. Over the centuries, the experiential combination of these three ingredients as an ointment has led to stronger wound healing and pain reduction properties. Saqez ointment is an effective, simple, inexpensive, completely herbal and non-invasive healing method without any side-effects and is thus particularly important in the treatment of nipple fissure and pain.

\section{Acknowledgments:}

This article is derived from a master's degree in midwifery from Shahid Beheshti University of Medical Sciences. Hereby, the authors would like to express their gratitude to the Research Deputy of the university and its School of Nursing and Midwifery, the directors of the affiliated health centers, especially Samarghandi center, and all the participants who invested their time and energy into the study.

\section{Trial Registration:}

The trial was registered at the Iranian Registry of Clinical Trials (http://www.irct.ir) with the Irct ID: IRCT2015080723535N1.

\section{Funding:}

The authors received no financial support for the research, authorship, and/or publication of this article.

\section{Conflict of Interest:}

There is no conflict of interest to be declared.

\section{Authors' contributions:}

All authors contributed to this project and article equally. All authors read and approved the final manuscript.

\section{References:}

1) Cunningham FG, Leveno KJ, Bloom SL, Spong CY, Dashe JS, Hoffman BL, et al. Williams Obstetrics 24th edition. New York.: McGraw Hill Professional. 2014; 673.

2) Tafazoli M, Saeedi R, Gholami Robatsangi M, Mazloom SR. Aloevera gel Vs.lanolin ointment in the treatment of nipple sore: a randomized clinical trial. TUMJ. 2010; 67 (10): 699-704. 
3) Eidelman AI, Schanler RJ, Johnston M, Landers S, Noble L, Szucs K, et al. Breastfeeding and the use of human milk. Pediatrics. 2012; 129 (3): e827- e841. doi: 10.1542/peds.2004-2491. PMID: 15687461.

4) Shanazi M, Khalili AF, Kamalifard M, Jafarabadi MA, Masoudin K, Esmaeli F. Comparison of the effects of lanolin, peppermint, and dexpanthenol creams on treatment of traumatic nipples in breastfeeding mothers. J Caring Sci .2015;4 (4): 297-307. doi: 10.15171/jcs.2015.030. PMID: 26744729. PMCID: PMC4699508.

5) Amir Ali Akbari S, Alamolhoda SH, Baghban AA, Mirabi P. Effects of menthol essence and breast milk on the improvement of nipple fissures in breastfeeding women. J Res Med Sci. 2014; 19 (7):629-633. PMID: 25364362. PMCID: PMC4214021.

6) Kazemirad M KN, Salamzadeh J,Nasiri N,Kazemi M,Moattar F. Comparison of Calendit -E Cream Versus Expressed Breast Milk on Nipple Crack's Treatment in breast feeding women. scientific \& research journal of Nursing\&Midwifery faculty, Shahid Beheshti University of Sciences. 2013; 23 (80): 1-9.

7) Tafazoli M, Ebrahimi Ameneh, Mohammad zadeh Ashraf,Esmaeely Habibolah. The effect of correcting breast feeding conditon on the prevention of breast fissure. Iran J Obstet Gyneco Infert. 2015;17 (138): 10 17.

8) Cooper MA. Myles midwifery. Second edition. Tehran,Mahtab Publishing. 2012; 2: 11-324.

9) Abd-Elsalam S, Hamido S, Abd el Hameed H. Effect of Using Pharmacological versus Alternative Therapy on Traumatic Nipples for Lactating Mothers. J Am Sci. 2011; 7 (11): 485-96.

10) Barakati S H SaS, Alayi SH,Farivar M, Homayoonfar N. a guide for breastfeeding mothers, mothers' answers to common questions. Minis Health Med Educ - UNICEF. 2011; 20000: 1-67.

11) Pugh LC, Buchko BL, Bishop BA, Cochran JF, Smith LR, Lerew DJ. A comparison of topical agents to relieve nipple pain and enhance breastfeeding. Birth. 1996; 23 (2): 88-93. doi: 10.1111/j.1523536X.1996.tb00835.x, PMID: 8826172.

12) Lavergne NA. Does application of tea bags to sore nipples while breastfeeding provide effective relief? J Obstet Gynecol Neonatal Nurs. 1995; 26 (1):53-58. doi: 10.1111/j.1552-6909.1997.tb01507.x. PMID: 9017547.

13) Sheinizadeh-Emadi S, Ehsani P, Dahanzadeh S, Haghighizadeh M. Comparison evaluation of Curcumin (Curcuma longa extract) with the application of expressed breast milk in the treatment of nipple cracks in lactating primiparous women: A randomized clinical trial. J Clin Nurs Midwifery. 2015; 4 (2): 11-19.

14) Dennis C-L, Schottle N, Hodnett E, McQueen K. An all-purpose nipple ointment versus lanolin in treating painful damaged nipples in breastfeeding women: A randomized controlled trial. Breastfeeding Med. 2012; 7 (6): 473-479. doi: 10.1089/bfm.2011.0121. PMID: 22428572.

15) Brent N, Rudy SJ, Redd B, Rudy TE, Roth LA. Sore nipples in breast-feeding women: a clinical trial of wound dressings vs conventional care. Arch Pediatr Adolesc Med. 1998; 152 (11): 1077-1082. doi: 10.1001/archpedi.152.11.1077, PMID: 9811284.

16) Cadwell K, Turner-Maffei C, Blair A, Brimdyr K, McInerney ZM. Pain reduction and treatment of sore nipples in nursing mothers. J Perinat Educ. 2004;13(1): 29-35. doi: 10.1624/105812404X109375. PMID: 17273373. PMCID: PMC1615851.

17) Livingstone V, Stringer LJ. The treatment of Staphyloccocus aureus infected sore nipples: a randomized comparative study. J Hum Lact. 1999;15 (3): 241-246. doi: 10.1177/089033449901500315. PMID: 10578803.

18) Gosha JL, Tichy AM. Effect of a breast shell on postpartum nipple pain: An exploratory study. J Nurse Midwifery. 1988;33 (2): 74-77. PMID: 3361356.

19) Ziemer MM, Cooper DM, Pigeon JG. Evaluation of a dressing to reduce nipple pain and improve nipple skin condition in breast-feeding women. Nurs Res. 1995; 44 (6): 347-351. doi: 10.1097/00006199199511000-00005, PMID: 7501488.

20) Newton N. Nipple pain and nipple damage: Problems in the management of breast feeding. J Pediatr. 1952;41 (4): 411-423. doi: 10.1016/S0022-3476(52)80124-6, PMID: 12991174.

21) Essa RM, Ebrahim EM. Effect of Breast Milk versus Therapeutic Honey (Apicare) on Cracked Nipples' healing. Life Sci J. 2013;10 (1): 2137-2147.

22) Chaves MEdA, Araújo AR, Santos SF, Pinotti M, Oliveira LS. LED phototherapy improves healing of nipple trauma: a pilot study. Photomed laser surg. 2012; 30 (3): 172-178. doi: 10.1089/pho.2011.3119. PMID: 22283620.

23) Marrazzu A, Sanna MG, Dessole F, Capobianco G, Piga MD, Dessole S. Evaluation of the Effectiveness of a Silver-Impregnated Medical Cap for Topical Treatment of Nipple Fissure of Breastfeeding Mothers. Breastfeed Med. 2015; 10 (5): 232-238. doi: 10.1089/bfm.2014.0177. PMID: 25989381. 
24) Kuşcu N, Koyuncu F, Lacin S. Collagenase treatment of sore nipples. Int J Gynaecol Obstet. 2002; 76 (1): 81-82. doi: 10.1016/S0020-7292(01)00550-1, PMID: 11818100.

25) Mohammadzadeh A, Farhat A, Esmaeily H. The effect of breast milk and lanolin on sore nipples. Saudi med J. 2005;26 (8):1231-1234. PMID: 16127520.

26) As'adi N, Kariman N, Shahrahmani H, Ghalandari S and Khodakarami N. A systematic review of clinical trials in the treatment of sore nipples and nipple pain in breastfeeding women. Iran J Obstet Gyneco Infert. 2016; 19: 22-33.

27) Buck ML, Amir LH, Donath SM. Topical Treatments Used by Breastfeeding Women to Treat Sore and Damaged Nipples. Clinical Lactation. 2015; 6 (1): 16-23. doi: 10.1891/2158-0782.6.1.16.

28) Walker M. Are There Any Cures for Sore Nipples? Clinical Lactation.. 2013;4 (3):106-115. doi: 10.1891/2158-0782.4.3.106.

29) Bozorgi M, Memariani Z, Mobli M, Salehi Surmaghi MH, Shams-Ardekani MR, Rahimi R. Five Pistacia species (P. vera, P. atlantica, P. terebinthus, P. khinjuk, and P. lentiscus): a review of their traditional uses, phytochemistry, and pharmacology. Sci World J. 2013; 2013: 1-33. doi: 10.1155/2013/219815. Article ID 219815.

30) Bahmani M, Saki K, Asadbeygi M, Adineh A, Saberianpour S, Rafieian-Kopaei M, et al. The effects of nutritional and medicinal mastic herb (Pistacia atlantica). J Chem Pharm Res. 2015; 7 (1): 646-653.

31) Haghdoost F, Baradaran Mahdavi MM, Zandifar A, Sanei MH, Zolfaghari B, Javanmard SH. Pistacia atlantica resin has a dose-dependent effect on angiogenesis and skin burn wound healing in rat. Evid Based Complement AlternatMed. 2013; 1-8. doi: 10.1155/2013/893425. PMID: 24285978. PMCID: PMC3826334.

32) Storr GB. Prevention of nipple tenderness and breast engorgement in the postpartal period. J Obste, Gynecol Neonatal Nurs. 1988; 17 (3): 203-209. doi: 10.1111/j.1552-6909.1988.tb00426.x, PMID: 3392623.

33) Ferreira-Valente MA, Pais-Ribeiro JL, Jensen MP. Validity of four pain intensity rating scales. PAIN ${ }^{\circledR}$. 2011;152 (10): 2399-2404. doi: 10.1016/j.pain.2011.07.005. PMID: 21856077.

34) McClellan HL, Hepworth AR, Garbin CP, Rowan MK, Deacon J, Hartmann PE, et al. Nipple pain during breastfeeding with or without visible trauma. J Human Lactation. 2012; 28 (4): 511-521. doi: 10.1177/0890334412444464. PMID: 22689707.

35) Farrar JT, Troxel AB, Stott C, Duncombe P, Jensen MP. Validity, reliability, and clinical importance of change in a 0-10 numeric rating scale measure of spasticity: a post hoc analysis of a randomized, doubleblind, placebo-controlled trial. Clin ther. 2008;30 (5): 974-985. doi: 10.1016/j.clinthera.2008.05.011. PMID: 18555944.

36) ALamolhoda SH, Amir Ali Akbari S, Akbarzadeh A, Esmaeely S. The effect of aloe vera gel on the breast fissures in lactating women. J Pejouhandeh. 2014; 97 (1): 13-17.

37) Saeidi R,Tafazoli M, Gholami M, Mazloom R. New treatment for nipple soreness in breastfeeding mothers: A clinical trial study. IJN. 2015; 6 (2): 48-51.

38) Munro BH. Statistical methods for health care research: Lippincott Williams \& Wilkins; 2005.

39) Esmaeilli H,Shakeri Mt, Salmani F, Jabari Noghabi H, Dalirsani Z. Drug Therapy for Psychological Disorders of Patients with Lichen Planus: A Longitudinal Ordinal study. J Mash Dent Sch. 2011; 35 (3): 157-64.

40) Rezaee Ghahrodi Z, Ghanjali M, Harandi F. Transitional model to analyze longitudinal data with the bivariate mixed ordinal and nominal responses. J. Statist. Res. Iran. 2008; 5 (1): 75-94. doi: 10.18869/acadpub.jsri.5.1.75

41) Abou-Dakn M, Fluhr JW, Gensch M, Wockel A. Positive effect of HPA lanolin versus expressed breastmilk on painful and damaged nipples during lactation. Skin Pharmacol Physiol. 2011; 24 (1). doi: 10.1159/000318228. PMID: 20720454.

42) Asgarirad H. PFAK. Preparation and Standardization of Therapeutic Bees Wax. J Babol University Medical Sciences. 2004; 24:12-16.

43) Aeenechi Y A. Materia Medica and Medicinal Plants of Iran. first ed: Tehran university. 1999; 1: 1-1208.

44) Saadatian S. E EDS, Mahdavi Shahri N, Fereidoni M, Niazmand S \& Rakhshandeh H. Investigating the effect of Curcuma longa and ghee on experimental gastric ulcers in rats. J cell and tissue. 20156 (2):12334.

45) Guyton AS HJ. Textbook of medical physiology. 12 ed: Tehran, Andishe Rafi. 2011; 2: 697-1335 